Saeed Na'amnh $\bowtie$

István Husti

Miklós Daróczi

https://doi.org/10.21278/TOF.453026921

ISSN 1333-1124

eISSN 1849-1391

\title{
IMPLEMENTING THE AUGMENTED REALITY AS AN INDUSTRY 4.0 APPLICATION TO SIMPLIFY THE BUSBAR BENDING PROCESS DURING THE COVID-19 PANDEMIC
}

\begin{abstract}
Summary
Skilled operators have a vital role in Industry 4.0 manufacturing, especially in a small manufacturing environment. To implement Industry 4.0 concepts, it is necessary to find an innovative solution that will improve the skills of operators in manufacturing. Augmented reality (AR) has become a part of this innovative solution by providing interactive live guidance, i.e. easy transfer of information to operator, especially the production, assembly and maintenance information. This paper demonstrates a simple method for implementing AR, particularly in small enterprises. It also shows benefits of implementing AR: the production quality is improved by offering an interactive and reliable training for technicians to improve their skills, which leads to the minimisation of errors occurring during the production. Moreover, this paper sheds light on the industry trends during the COVID-19 pandemic and presents the effectiveness of augmented reality during the pandemic. A real example has been implemented on a busbar bending process in order to simplify the task of the operator especially when the complex bent shape is produced.
\end{abstract}

Key words: augmented reality (AR), Industry 4.0, bending process, busbar

\section{Introduction}

Augmented reality is defined by Milgram and Kishimo as a technique that improves the reality by superimposing a layer of information and numerical contents [1]. Fig. 1 presents this definition briefly. Azuma defined augmented reality as the reality which "supplements the real world with virtual (computer-generated) objects that appear to coexist in the same space as in the real world" [2]. He also demonstrated the difference between augmented reality (AR) and augmented virtuality (AV). In case of AV real elements are added to virtual objects and the surrounding environment is virtual, while in AR the surrounding environment is real and many real elements occur. 


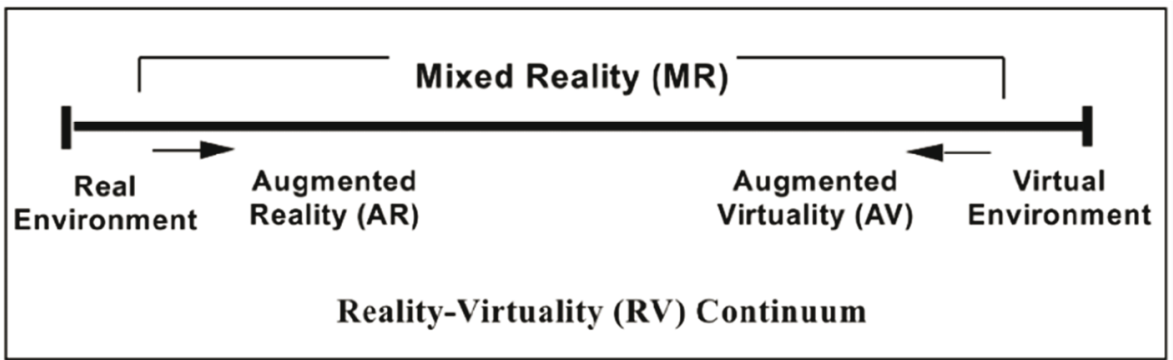

Fig. 1 Reality-virtuality continuum (AV) [1]

Although intelligent automation has been strongly promoted, humans still have an essential role in manufacturing operations [3]. The Industry 4.0 concepts do not concentrate on 'dark factories' without humans, but intend to enable people to work in smart factories [4] parallel with intelligent manufacturing systems. The augmented operator paradigm depends on the worker's technological support that is needed in the manufacturing environment, which represents a real challenge since the operators will face several new tasks [3]. IAR is categorised as one of the most important elements that will improve the smart factory development [5] by creating smooth human-machine interactions by visualising interactive and contextual information [6] to simplify the human-production systems interaction using digital data. Many researchers concentrate on how to utilize AR in industry, but it is still vague how to implement this technology properly. Thus, to raise productivity, the capability to sense, monitor, characterise, and help workers in highly complex tasks has become a necessity, especially when performing dangerous or exhausting tasks in order to remain competitive. Researchers and engineers have been trying to find solutions by applying emerging technologies, such as virtual reality (VR) and augmented reality (AR) technologies, artificial intelligence (AI) and Internet-of-Things (IoT) [7].

The spread of new technologies is often obtained by attempts to introduce them into an educational environment [8]. A fast adaptation to smartphones came with the new innovations that simplified the access to VR and AR to almost everyone [9]. The main challenge in implementing AR is the cost. Applying AR in industry is still exclusively for the rich companies, whilst for small enterprises it is still questionable whether applying AR could help or not. High cost of AR makes leaders of small enterprises think that this technology is a kind of fancy innovation and from this point of view a new obstacle arises, namely how to make the leaders satisfied with the implementation of AR.

This paper demonstrates a very simple, cheap and applicable method for training operators in their workplace in any enterprise. The proposed method enables the operator to use his/her mobile phone to perform the task duly. A case study was carried out on a bending machine to produce a required shape of busbar.

\subsection{Busbar overview}

Busbars are strips of metal, such as copper or aluminium (Fig. 2), used for providing power within an electrical system. Thickness of busbars may vary according to usage and requirements. Busbars usually have to be connected to transmit power between two electrical systems. Typically, busbars are covered with an insulating material between conductors. Reducing the number of cable connections is one of the main purposes of using busbars, which is significant for the elimination of the problem of high-density electronic systems. There are several benefits of using busbars, such as low inductance, high electricity transmission, it is easy to assemble them and they fit in different places [10]. Busbars are widely spread and used in several areas, such as aviation industry, automotive industry, ships, lighting industry and military electronic devices. Currently, the busbar is a significant part in 
electrical vehicles, such as forklifts or electrical cars, as these vehicles mainly use busbars as a typical component of their batteries. This paper focuses on using augmented reality (AR) to improve the productivity of the process of bending busbars to reduce the number of scrap parts and promote the training methods as one of the Industry 4.0 application.

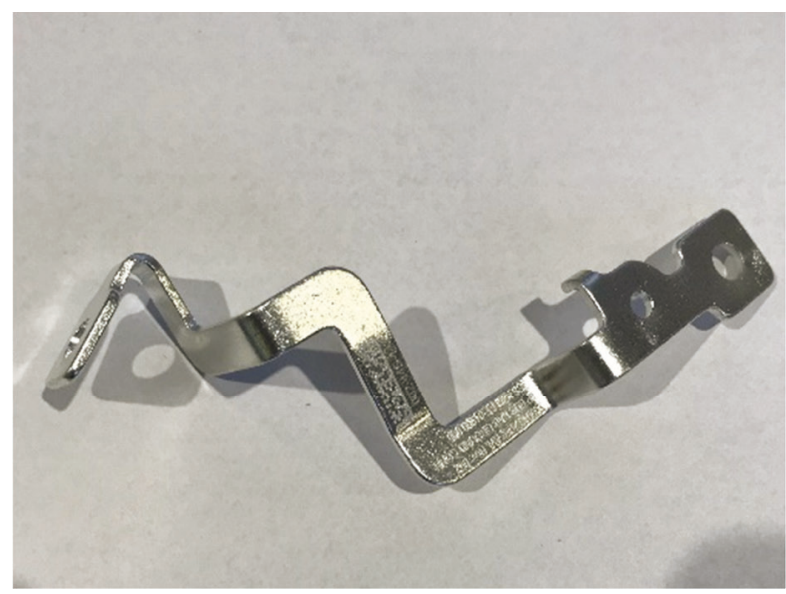

Fig. 2 Aluminium busbar ground connection

\section{Related work}

The Industry 4.0 concept implies that the process plans have to be defined more often than in the conventional manufacturing method in which products are less variable and less often customized for a single user. This raises a possibility of making errors and of unoptimized process plan, which leads to an increase in costs and a decrease in the product quality [11]. Nowadays, several companies consider AR as an essential method for acquiring modern and novel services to present their products [12]. By giving flexible real-time information and a possibility of gaining information hands-free IAR can provide a benefit of high efficiency [13] by reducing errors [14] such as assembly errors and it provides a simple way of communication with experts in maintenance services [15]. Training or even assembly operations can be achieved by IAR [16] or very likely as a live guidance for operators [17].

The noticeable reductions in time, errors, and training requirements have been illustrated by the Augmented Reality for Enterprise Alliance (AREA) of Boeing, which stated "This has tremendous potential to minimise errors, cut down on costs and improve product quality" [18]. General Electric (GE) achieved an increase in productivity and efficiency by applying AR. Honeywell also achieved success in operator training by implementing AR.

In 1940 and during the Second World War the concept of training within industry (TWI) was introduced by the U.S. government. More than eight million people were unemployed during that era. The main goal of TWI was to support the defence industry with highly skilled workers to increase the productivity of the defence production. The U.S. government aimed to promote production by defining three standardized training programmes:

1. Job Instruction Training (JI): In this programme supervisors were trained to teach new employees to remember to do a job properly and safely.

2. Job Method Training (JM): In this programme supervisors were trained to develop job techniques to produce high quantities with high quality products in less time.

3. Job Relations Training (JR): In this programme supervisors were trained to lead employees and to give them an analytical method for efficient problem solving. 
The impact of using TWI was considerable in more than 600 companies between 1941 and 1945 , namely, thanks to TWI the production increased by $86 \%$ and helped to reduce the training time by $80 \%$ [19]. TWI attracted the Japanese after the Second World War; this training method became fundamental in their approach to production especially after Japanese production fell down to ten percent in 1935.

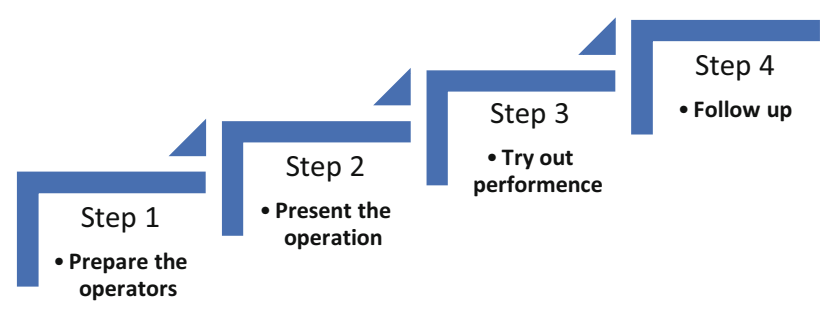

Fig. 3 Four steps developed by Japanese government to train operators [20]

A standardised four step method (Fig. 3) was adopted in order to train junior operators. This approach was mainly used for assembly and maintenance [20]. The four-step method is summarised as follows:

Step 1: Prepare the operator

This step makes the operator getting interested in learning his new job. The trainer concentrates on analysing the operator's existing knowledge and tries to arrange a comfortable work environment for the trainee.

Step 2: Present the operation

At this step, the trainer has to explain the task, presents every step in a successive manner and clarifies the main factors that may affect the product quality.

Step 3: Try out performance

The trainee must implement the task under the supervision of the trainer and the trainer is responsible for correcting the trainee's mistakes if required. The new trainee should repeat, understand and explain every key point, to make sure that he or she comprehends the job.

\section{Step 4: Follow up}

Once the trainee implements the task correctly, the trainer has to check the new trainee regularly to know if he or she still works properly or not.

This four-step method is still the most important approach in the automotive industry. Currently, augmented reality considers auspicious techniques for training. Moreover, the expected developments in training, production quality and time management are extremely precious. AR has been proven to be an effective way to support the operator during the stepby-step instruction in the interactive environment, which definitely leads to avoiding errors during the implementation of the task.

\section{Approach and methodology}

Augmented reality is applied on the busbar production line at Nematech $\mathrm{Kft}$, a company of the Froetek GmbH group. The produced busbars are used as the main component of the battery pack in electric vehicles (Fig. 4). 


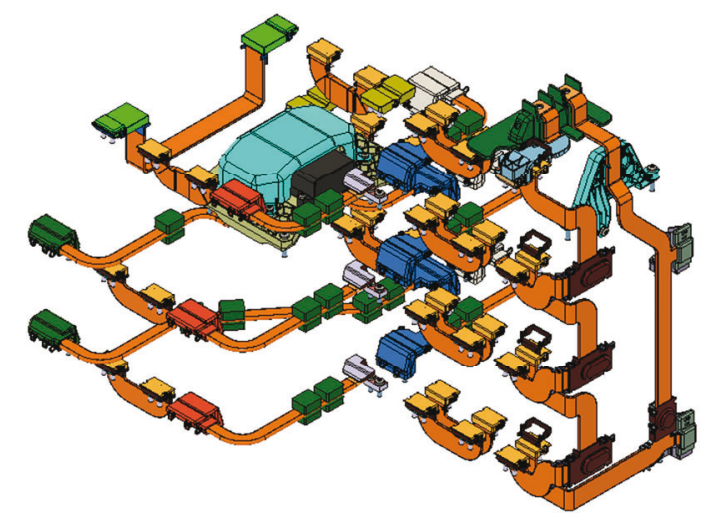

Fig. 4 Busbars used in the assembly of a battery pack

Many steps should be implemented in the production of busbars. These steps depend on the usage of the product. For example, to produce an aluminium busbar ground connection (Fig. 2) the following processes should be implemented (Fig. 5):

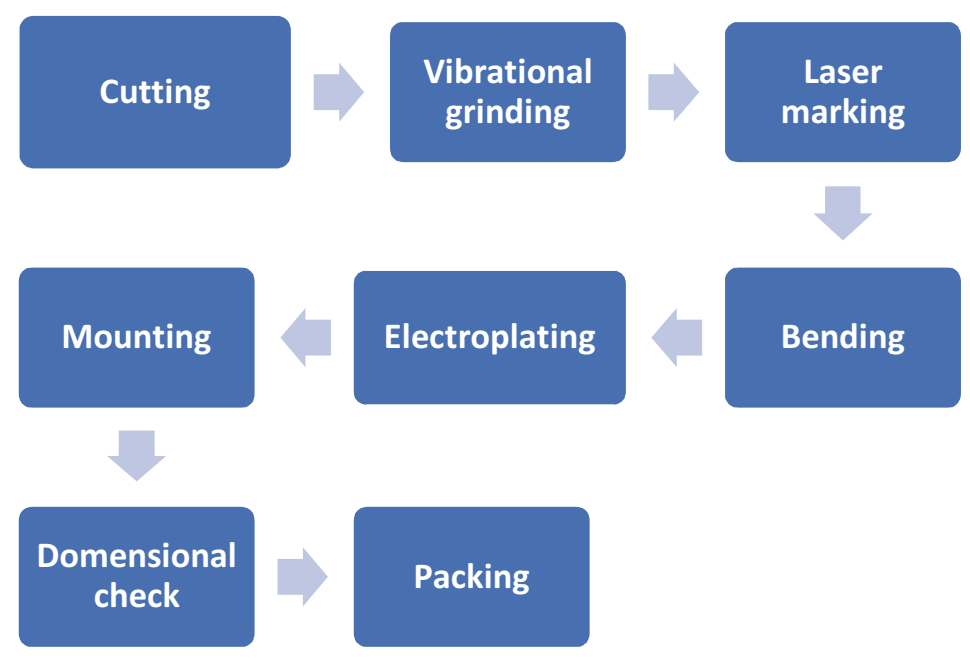

Fig. 5 Process flow illustrating the production of aluminium busbar ground connection

Within the whole process flow, the bending step was a challenge, because due to the complexity of the final shape a huge number of parts became scrap. Unclear bending drawings, complex bending shapes and the nature of the bending process which depends on the operator are the main reasons the final bending was incorrect. Moreover, the majority of the operators depend on the drawings and on their memory of how to make the bending. If an operator works with a large number of different parts with different bending shapes, that can definitely confuse him/her and he/she would be unable to complete the task efficiently.

Several errors were detected during the process of bending the aluminium busbar ground connection. These errors are:

1. Wrong die or wrong punch are used.

2. The starting point of the bending is in the wrong position (Fig. 6).

3. The bending direction is wrong (Fig. 7).

Minor problems may also come up, especially during the COVID-19 pandemic, when many companies reduced the number of workers and have been working with less capacity, resulting in decreased production. Moreover, skilled operators may not be able to come to 

during the Covid-19 Pandemic

work because of the COVID-19 policies, which means that unskilled operators have to perform the tasks. To overcome this problem AR is the best choice to keep the sustainability of production. Fig. 8 shows the approach used to achieve the bending using AR, i.e. using the Edrawings Pro software. Users can download the software as a mobile app, and it is available in both versions, IOS or Android. In this experiment, iPhone 7 camera was used as an AR detector and a BOUSCHERT Profi 28 bending machine was also used to achieve the bending. It is relatively easy to apply the proposed approach with the following steps:

Step 1: The operator has to upload the CAD models into Edrawings app.

Step 2: These models have to be ordered step by step into the operator's mobile.

Step 3: The operator selects the first step of bending and detects the marker by using his/her phone camera.

Step 4: The operator has to follow the steps until the final bending is done as shown in Figs 10-13.

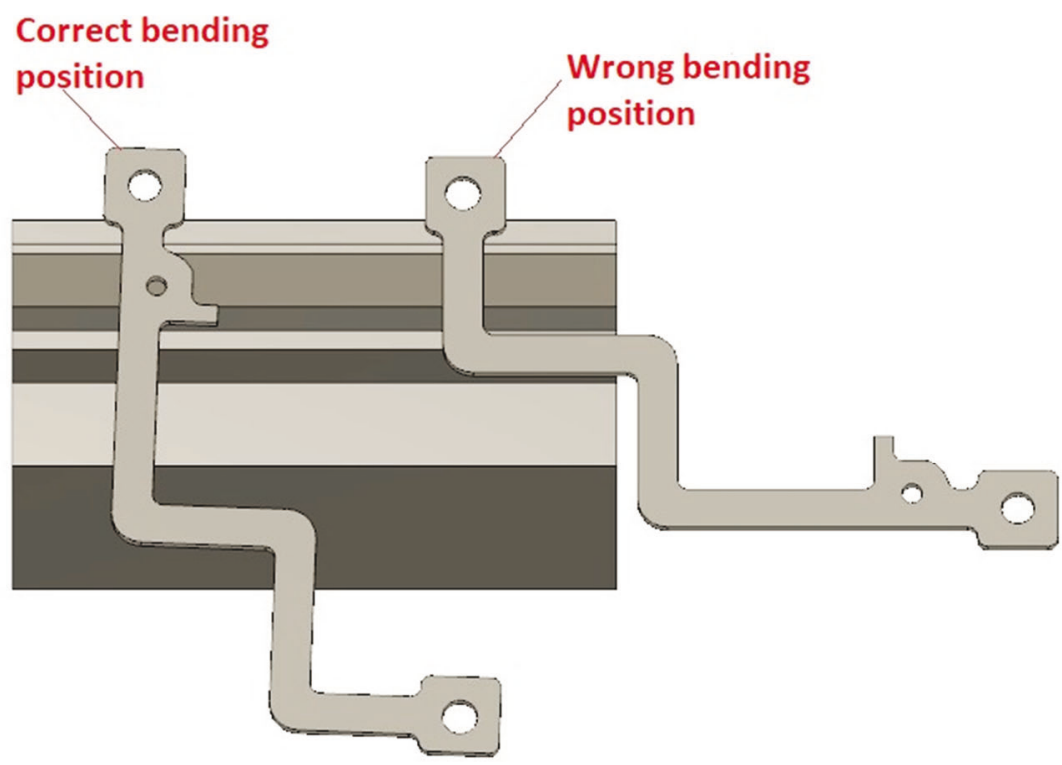

Fig. 6 Position of the bending starting point

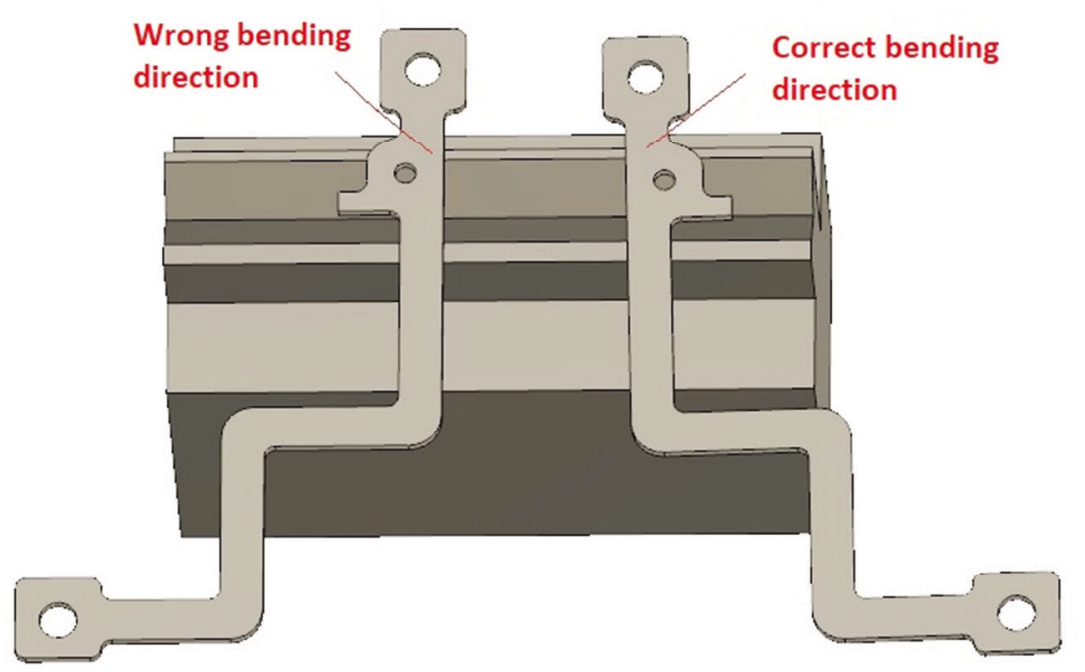

Fig. 7 Bending direction 

during the Covid-19 Pandemic

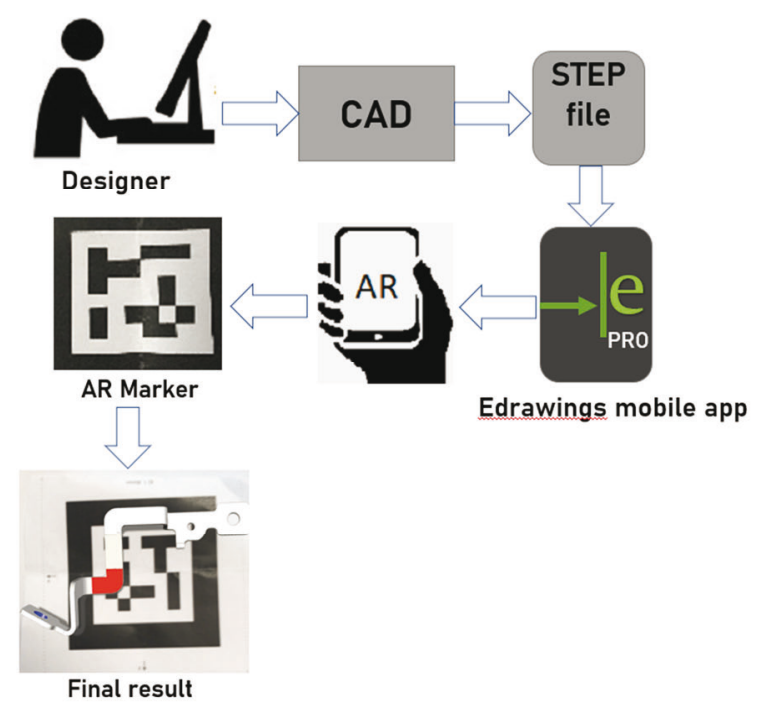

Fig. 8 AR schematic approach

\section{Results and discussion}

The use of the proposed method resulted in a noticeable progress, i.e. an accurate bending was achieved easily. Moreover, three untrained operators stated that they were delighted to use AR. AR makes the bending process interactive. Furthermore, there is no need to memorise the bending steps for each part. In addition, the scrap rate was noticeably reduced after using AR, Fig. 9. The age of operators was also taken into consideration to relate it to the performance of the operators during the bending process. The age of the operators was as follows: operator 1: 42 years of age, operator 2: 30 years of age and operator 3: 24 years of age.

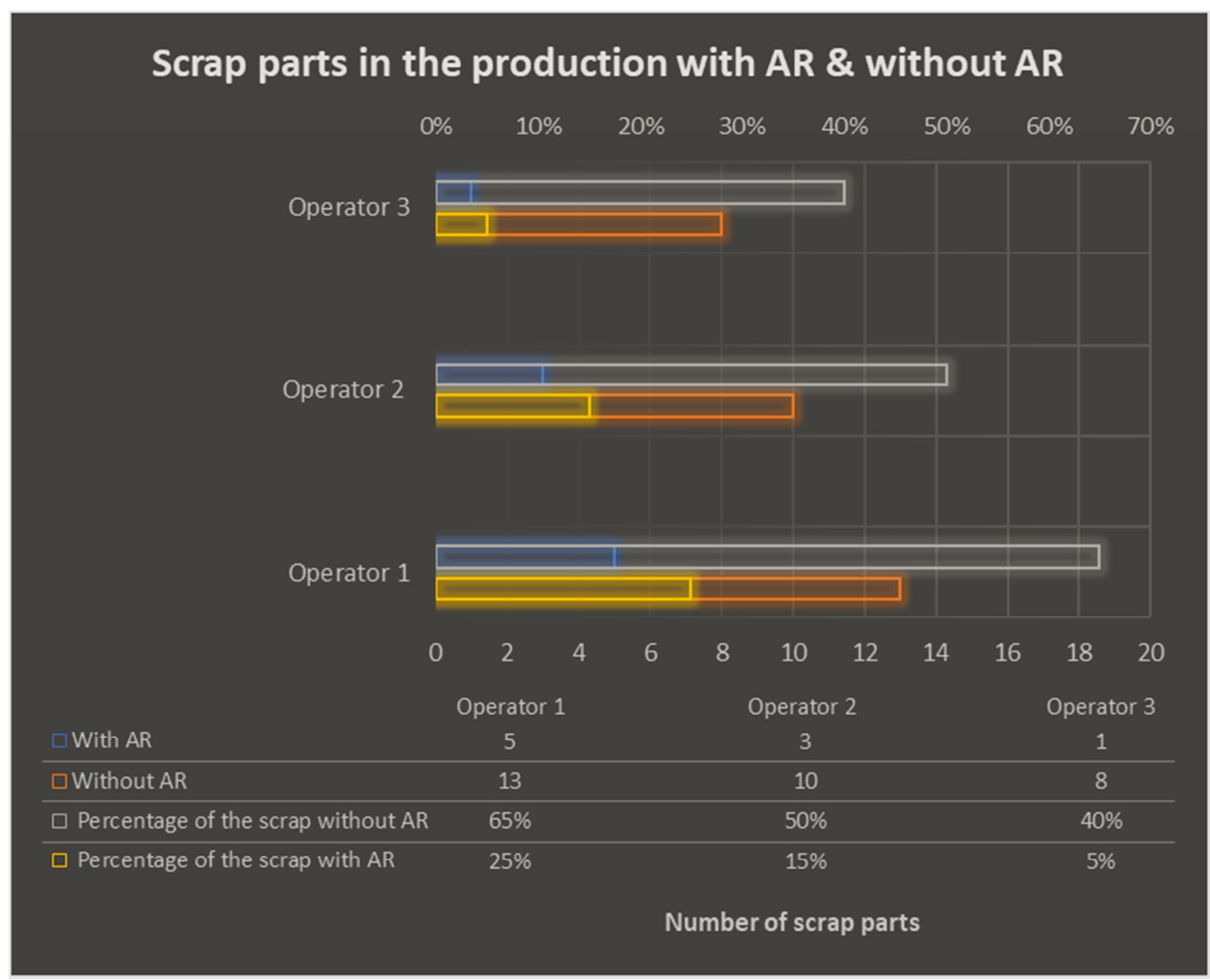

Fig. 9 Number of scrap parts in the production using AR and not using AR 

during the Covid-19 Pandemic

A set of 40 parts of the aluminium busbar ground connection (Fig. 2) was used by each operator, of which 20 parts were bent without using AR and 20 parts were bent using AR. The three operators had no experience on the bending machine. The first operator (42 years old) scrapped 13 parts out 20 without using AR (65\%), while after using AR five parts out of 20 had to be scrapped and the percentage of scrap decreased to $25 \%$. The second operator (30 years old) scrapped 10 parts without using AR (50\%), scrapped three parts when he used AR and the scrap percentage decreased to $15 \%$. The third operator ( 24 years old) had the best performance by getting 8 parts scrapped without using AR, which is $40 \%$ scarp, and only 5\% after using AR (one part scrapped). The reduction in the scrap number was tangible, which definitely leads to a reduction in the production costs and saves money. Meanwhile, the variation in numbers and performance among the operators can be attributed to the difference in age. Age plays a significant role in implicit and explicit memory according to Emma et al. [21], which means that the results show a good agreement with their research since the best performance was achieved by the youngest operator. In addition, the operators received a reliable and safe training and used AR. Fig. 10 demonstrates the steps of the process of bending an aluminium busbar ground connection. As shown in Fig. 10.a, the original busbar needs to be bent and seven bendings must be carried out in order to achieve the final product (Fig. 13. j).

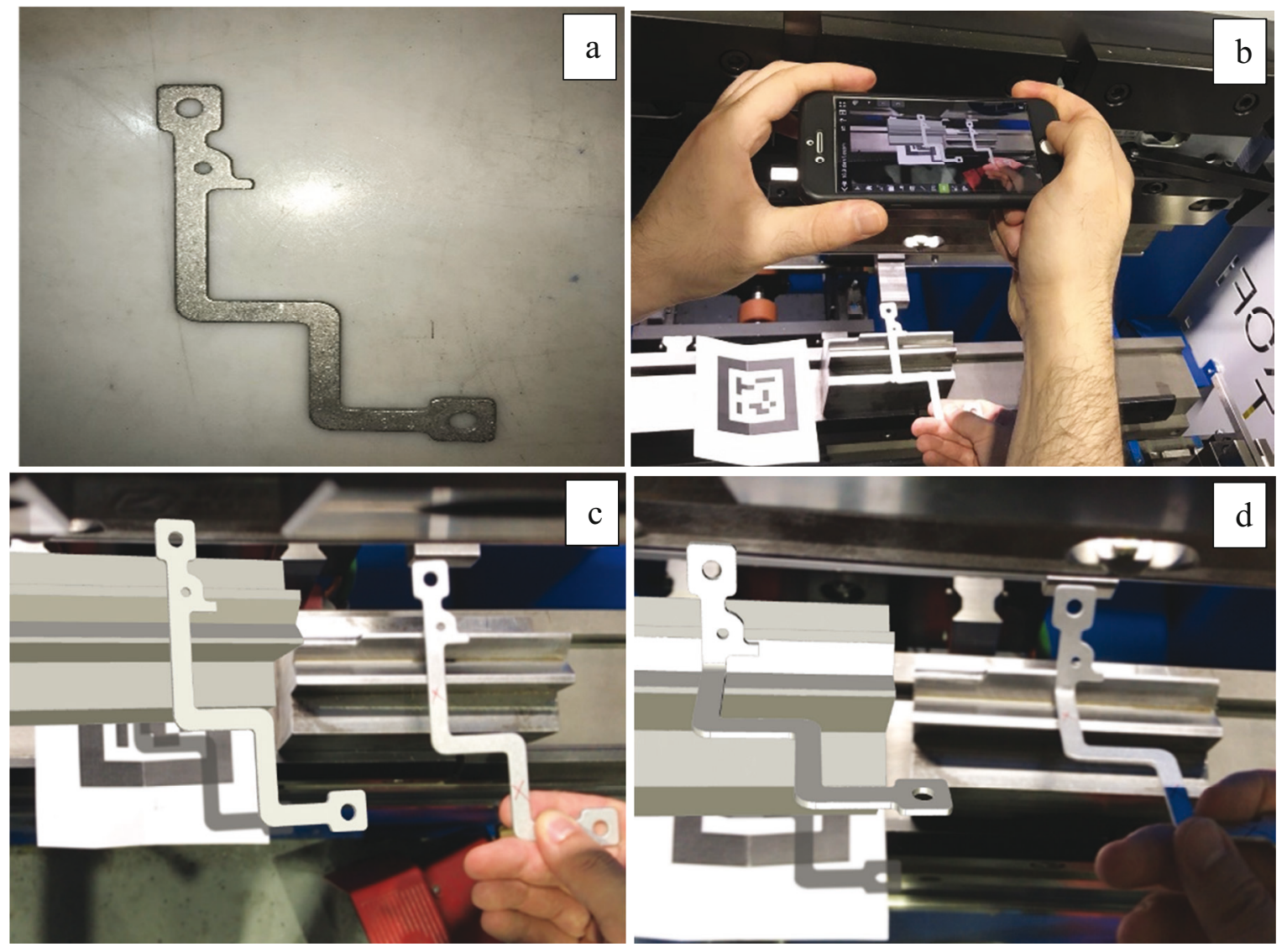

Fig. 10 Using AR to identify bending steps: a. the original part which is not yet bent, $\mathrm{b}, \mathrm{c}$ and $\mathrm{d}$ : bending in the first step during using AR

The benefits of using AR such as in distance training and 3D interactive guiding keep the sustainability of the production even during the COVID-19 pandemic and improve the productivity by decreasing operators' errors. All these benefits have been achieved by using a simple AR tool that is now available at low cost and has convenient functions, especially for small enterprises. 
Implementing the Augmented Reality as an Industry 4.0 Application to Simplify the Busbar Bending Process during the Covid-19 Pandemic
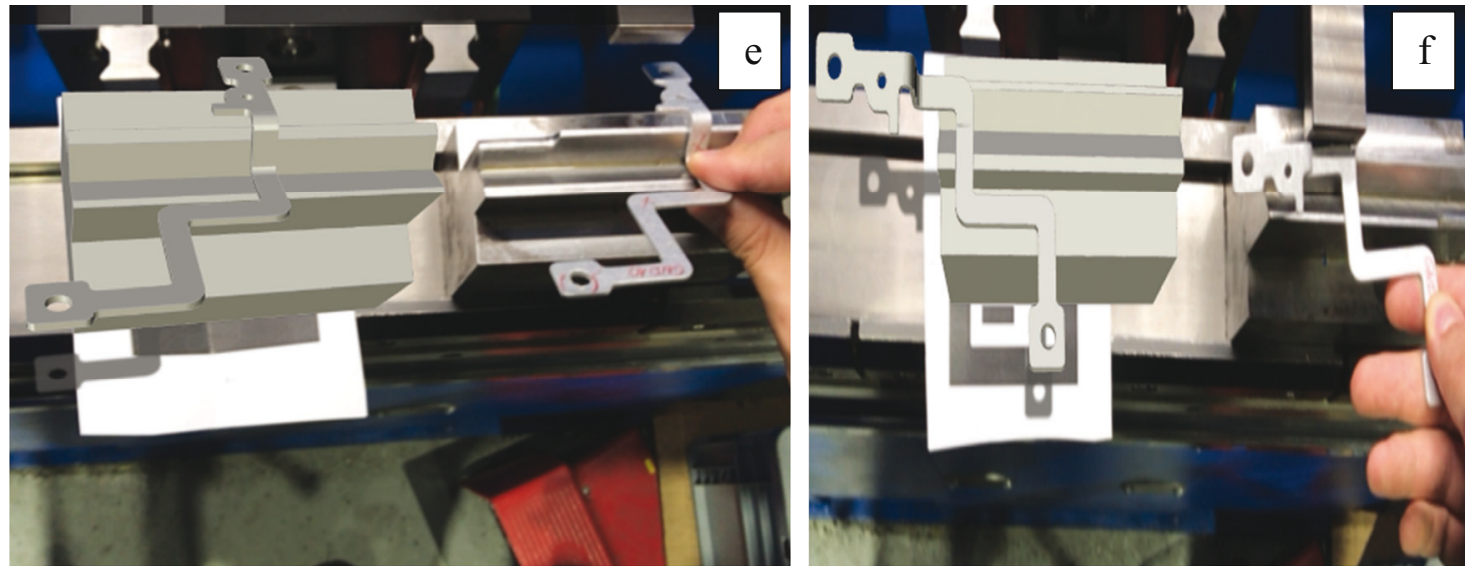

Fig. 11 e, f. Second and third bending using AR
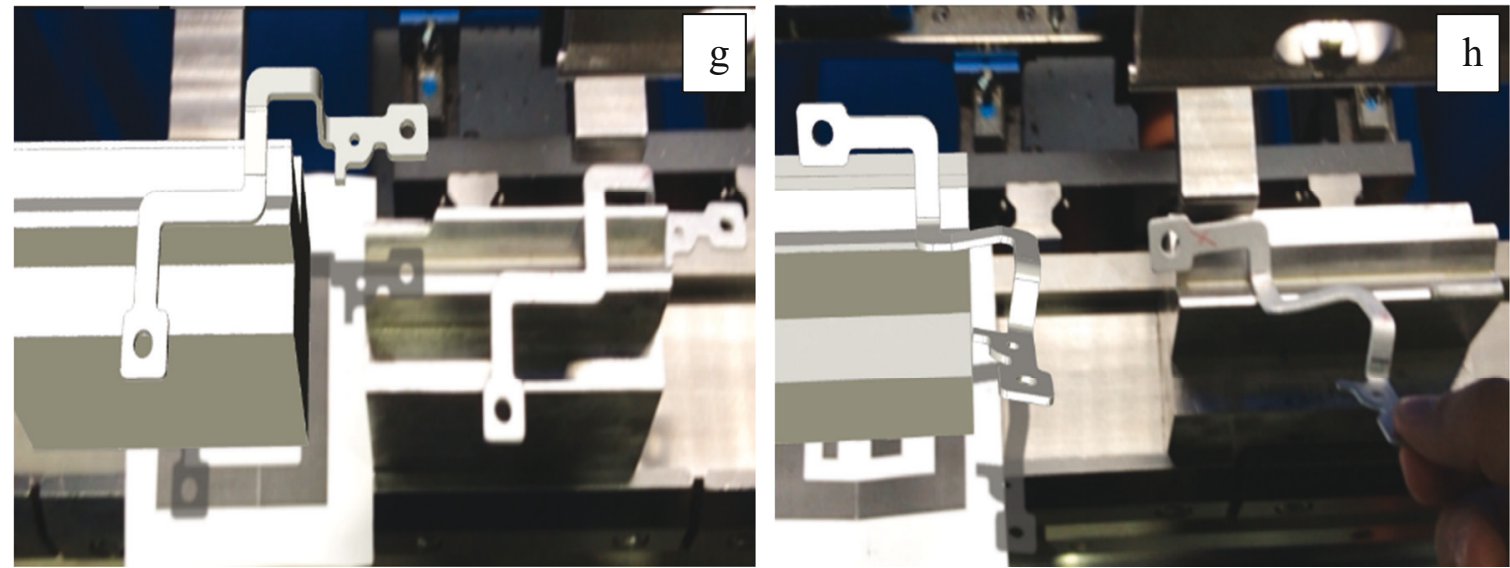

Fig. 12 g, h. Fourth and fifth bending using AR
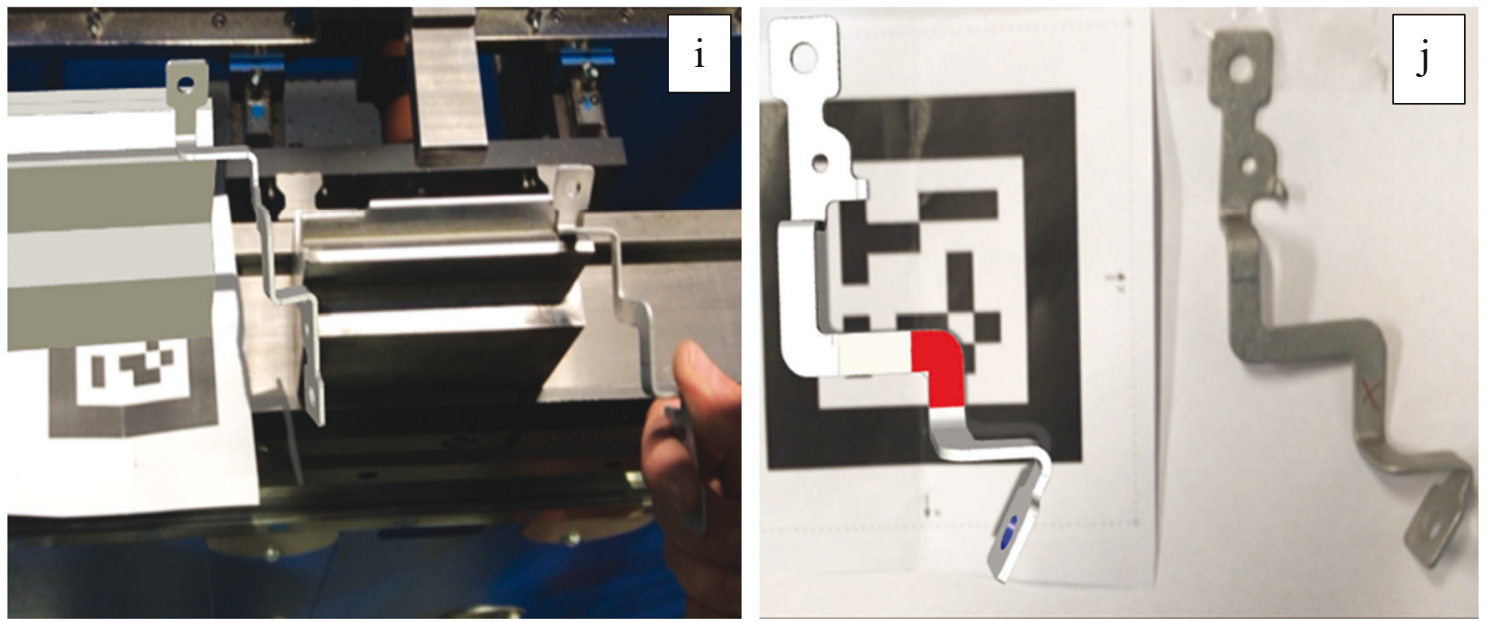

Fig. 13 i, j. Sixth bending and final product shape after using AR

The AR technology is no longer expensive and complicated equipment as it was in the past [22], and has been available to all enterprises, big or small. Technological development in Hungary is slow and there are many challenges in implementing new technologies in factories. However, currently many companies are looking for modern technologies and solutions to support their employees and to achieve digital transformation and sustainability in the production especially during the COVID-19 pandemic. Considering the potential features of the AR technology and the necessity of digital transformation (which is an ongoing process in many industrial fields), as well as the fact that the labourers' attitudes were generally 
Implementing the Augmented Reality as an Industry 4.0 Application to Simplify the Busbar Bending Process during the Covid-19 Pandemic

positive about using AR, integrating this technology as a training approach is highly promising. However, the questions related to the real influence of this technology need to be investigated in further future research.

\section{Conclusions}

This paper proposes a very simple method for implementing augmented reality. Busbar bending was taken as an example. The paper focuses on the benefits of using AR as a training tool and shows that the AR technology could be used in several industrial applications. Augmented reality is still a promising method, and it proved its efficiency during the COVID19 pandemic since many industrial parties have been forced to work with low capacity or even had to fire their employees. The presented experiment took place at Nematech KFT, where AR was used for training in order to decrease the amount of scrap. The results were impressive and showed that AR should be used in the development of industrial training methods. In addition, the age of the operator was taken into account and the results indicated that the performance of the operator's memory had a direct relation with age as also proved by previous studies. However, the study has a limitation: the sample size was not big enough; only three persons participated, so we cannot generalize from these few examples.

\section{REFERENCES}

[1] K. F. MILGRAM P, “A taxonomy of mixed reality visual displays,” IEICE Trans. Inf. Syst., no. 77(12), pp. 1321-1329. 1994, 1994.

[2] R. Azuma, Y. Baillot, R. Behringer, S. Feiner, S. Julier, and B. MacIntyre, "Recent advances in augmented reality," IEEE Comput. Graph. Appl., vol. 21, no. 6, pp. 34-47, 2001, https://doi.org/10.1109/38.963459

[3] A. C. Pereira and F. Romero, "A review of the meanings and the implications of the Industry 4.0 concept,” Procedia Manuf., vol. 13, pp. 1206-1214, 2017, https://doi.org/10.1016/j.promfg.2017.09.032

[4] A. Rashid, T. Masood, J. A. Erkoyuncu, B. Tjahjono, N. Khan, and M. Shami, "Enterprise systems' life cycle in pursuit of resilient smart factory for emerging aircraft industry: a synthesis of Critical Success Factors'(CSFs), theory, knowledge gaps, and implications," Enterp. Inf. Syst., vol. 12, no. 2, pp. 96-136, Feb. 2018, https://doi.org/10.1080/17517575.2016.1258087

[5] R. Davies, "Industry 4.0 Digitalisation for productivity and growth,” Eur. Parliam. Res. Serv., vol. 1, 2015.

[6] F. Longo, L. Nicoletti, and A. Padovano, "Smart operators in industry 4.0: A human-centered approach to improve operators' capabilities and competencies within the new smart factory context," Comput. Ind. Eng., vol. 113, pp. 144-159, Nov. 2017, https://doi.org/10.1016/j.cie.2017.09.016

[7] L. Hu et al., "Modeling of Cloud-Based Digital Twins for Smart Manufacturing with MT Connect," Procedia Manuf., vol. 26, pp. 1193-1203, 2018, https://doi.org/10.1016/j.promfg.2018.07.155

[8] M. Billinghurst, A. Clark, and G. Lee, “A Survey of Augmented Reality,” Found. Trends ${ }^{\circledR}$ HumanComputer Interact., vol. 8, no. 2-3, pp. 73-272, 2015, https://doi.org/10.1561/1100000049

[9] J. Martín-Gutiérrez, C. E. Mora, B. Añorbe-Díaz, and A. González-Marrero, "Virtual Technologies Trends in Education," EURASIA J. Math. Sci. Technol. Educ., vol. 13, no. 2, Jan. 2017, https://doi.org/10.12973/eurasia.2017.00626a

[10] Y. J. Bao, K. W. E. Cheng, K. Ding, and D. H. Wang, "The study on the busbar system and its fault analysis," 2013 5th Int. Conf. Power Electron. Syst. Appl. PESA 2013, 2013, https://doi.org/10.1109/PESA.2013.6828246

[11] M. Trstenjak and T. Opetuk, "Industry 4.0 Readiness Factor Calculation and Process Planning: State-ofthe-Art Review," Trans. FAMENA, vol. 44, no. 3, pp. 1-22, Nov. 2020, https://doi.org/10.21278/TOF.44301

[12] J. Zubizarreta, I. Aguinaga, and A. Amundarain, "A framework for augmented reality guidance in industry," Int. J. Adv. Manuf. Technol., vol. 102, no. 9-12, pp. 4095-4108, Jun. 2019, https://doi.org/10.1007/s00170-019-03527-2 
Implementing the Augmented Reality as an Industry 4.0

Application to Simplify the Busbar Bending Process during the Covid-19 Pandemic

[13] A. Guo et al., "A comparison of order picking assisted by head-up display (HUD), cart-mounted display (CMD), light, and paper pick list," in Proceedings of the 2014 ACM International Symposium on Wearable Computers - ISWC '14, 2014, pp. 71-78, https://doi.org/10.1145/2634317.2634321

[14] X. Wang, S. K. Ong, and A. Y. C. Nee, “A comprehensive survey of augmented reality assembly research," Adv. Manuf., vol. 4, no. 1, pp. 1-22, Mar. 2016, https://doi.org/10.1007/s40436-015-0131-4

[15] D. Mourtzis, A. Vlachou, and V. Zogopoulos, "Cloud-Based Augmented Reality Remote Maintenance Through Shop-Floor Monitoring: A Product-Service System Approach,” J. Manuf. Sci. Eng., vol. 139, no. 6, Jan. 2017, https://doi.org/10.1115/1.4035721

[16] S. Werrlich, K. Nitsche, and G. Notni, "Demand Analysis for an Augmented Reality based Assembly Training," in Proceedings of the 10th International Conference on PErvasive Technologies Related to Assistive Environments, Jun. 2017, pp. 416-422, https://doi.org/10.1145/3056540.3076190

[17] J. Blattgerste, B. Strenge, P. Renner, T. Pfeiffer, and K. Essig, "Comparing Conventional and Augmented Reality Instructions for Manual Assembly Tasks," in Proceedings of the 10th International Conference on PErvasive Technologies Related to Assistive Environments, Jun. 2017, pp. 75-82, https://doi.org/10.1145/3056540.3056547

[18] K. Kloberdanz, “'Smart specs: OK glass, fix this jet engine.' GE.cOm. 2020,” 2020, https:// www.ge.com/reports/smart-specs-ok-glass-fix-jet-engine/

[19] P. Graupp and R. J. Wrona, The TWI workbook: essential skills for supervisors. CRC Press, 2017.

[20] M. D. Mura, G. Dini, and F. Failli, “An Integrated Environment Based on Augmented Reality and Sensing Device for Manual Assembly Workstations," Procedia CIRP, vol. 41, pp. 340-345, 2016, https://doi.org/10.1016/j.procir.2015.12.128

[21] E. V. Ward, C. J. Berry, D. R. Shanks, P. L. Moller, and E. Czsiser, “Aging Predicts Decline in Explicit and Implicit Memory: A Life-Span Study,” Psychol. Sci., vol. 31, no. 9, pp. 1071-1083, Sep. 2020, https://doi.org/10.1177/0956797620927648

[22] M. Akçayır and G. Akçayır, "Advantages and challenges associated with augmented reality for education: A systematic review of the literature," Educ. Res. Rev., vol. 20, pp. 1-11, Feb. 2017, https://doi.org/10.1016/j.edurev.2016.11.002.

\footnotetext{
Submitted: $\quad 24.01 .2021$

Accepted: $\quad$ 05.7.2021
}

\author{
Saeed Na'amnh * \\ István Husti \\ Miklós Daróczi \\ Institute of Engineering Management, \\ Szent Istvan University, 2100 Gödöllő, \\ Hungary \\ *Corresponding author: \\ saeednaamneh1990@gmail.com
}

